\title{
BMJ Open Extracellular vesicle protein levels are related to brain atrophy and cerebral white matter lesions in patients with manifest vascular disease: the SMART-MR study
}

Danny A Kanhai, ${ }^{1}$ Dominique P V de Kleijn, ${ }^{2,3,4}$ L Jaap Kappelle, ${ }^{5}$
Cuno S P M Uiterwaal, ${ }^{6}$ Yolanda van der ${ }^{6}$ raaf, ${ }^{6}$ Gerard Pasterkamp, ${ }^{2}$
Mirjam I Geerlings, ${ }^{6}$ Frank L J Visseren, ${ }^{1}$ on behalf of the SMART Study Group

\section{ABSTRACT}

Kleijn DPV, Kappelle LJ, et al. Extracellular vesicle protein levels are related to brain atrophy and cerebral white matter lesions in patients with manifest vascular disease: the SMART-MR study. BMJ Open 2014;4: e003824. doi:10.1136/ bmjopen-2013-003824

- Prepublication history and additional material for this paper is available online. To view these files please visit the journal online (http://dx.doi.org/10.1136/ bmjopen-2013-003824).

Received 18 August 2013 Revised 14 November 2013 Accepted 4 December 2013

CrossMark

For numbered affiliations see end of article.

Correspondence to Dr Frank LJ Visseren; f.I.j.visseren@umcutrecht.nl follow-up.
Objectives: Extracellular vesicles (EVs) and their protein levels have been identified as a potential risk marker for the development of vascular disease. In the present study, we assessed whether levels of four previously identified EV proteins (cystatin C, serpin G1, serpin F2 and CD14) are associated with cerebral white matter lesions (WMLs) and brain atrophy.

Design: Cohort study; cross-sectional and prospective. Setting: Single centre, secondary and tertiary setting. Participants: 1309 patients with manifest vascular disease from the Second Manifestations of ARTerial disease-MR (SMART-MR) study, of which 994 had successful brain MRI and EV protein level measurements.

Outcomes: WML and brain parenchymal fraction (BPF), as parameter for brain atrophy, at baseline and

Statistical methods: The relationship between EV protein levels and WML volume (expressed as log transformed percentage of intracranial volume) and BPF (expressed percentage of intracranial volume) on $1.5 \mathrm{~T}$ brain MRI was assessed with multivariable linear regression modelling. Subsequently, the relationship between baseline EV protein levels and progression of atrophy and WML was analysed in 534 patients, in whom a follow-up MRI was obtained after 4 years.

Results: Higher EV-cystatin C and EV-CD14 were significantly associated with larger WML volume (linear regression coefficient $(95 \% \mathrm{CI}) 0.10 \log \% / \mathrm{SD}(0.04$ to 0.17 ) and $0.14 \log \% / S D(0.07$ to 0.20$)$, respectively. Higher EV-CD14 was associated with more brain atrophy $(-0.14 \% / S D ;-0.27$ to -0.01$)$. Baseline EV-CD14 was significantly associated with increase of WMLs $(0.11 \mathrm{log}$ $\% / S D(0.04$ to 0.18$)$ ). No relationship with EV-serpins was observed at baseline or at follow-up.

Conclusions: EV proteins cystatin C and CD14 are related to cerebral WMLs and the progression of brain atrophy in patients with manifest vascular disease, potentially identifying EVs in the aetiology of structural brain changes.

\section{Strengths and limitations of this study}

- Relatively large sample size.

- Follow-up measurements of brain parameters.

- Only four of the numerous protein levels were measured.

- Unclear how extracellular vesicles interact with the blood-brain barrier.

\section{INTRODUCTION}

Patients with manifest vascular disease often have morphological changes in the small vessels of the brain, characterised by white matter lesions (WML) on MRI. ${ }^{1}$ The exact underlying pathophysiological mechanism regarding WML remains unclear. WML have been associated with cognitive decline ${ }^{2}$ and may explain the increased risk for cognitive decline in patients with manifest vascular disease. ${ }^{3} 4$ Cognitive decline and vascular disease have more in common as they share important risk factors such as obesity, hypertension, dyslipidaemia and diabetes. ${ }^{5} 6$

Recently, extracellular vesicles (EVs) have been identified as a novel, independent risk marker for the occurrence of vascular disease. ${ }^{7} 8$ EVs are membrane-shed vesicles, between 50 and $1000 \mathrm{~nm}$ in diameter, released in the extracellular space after cell activation or apoptosis, and include various phenotypes such as microparticles and exosomes. ${ }^{9} 10 \mathrm{EVs}$ are defined by size and antigen expression, which depend on their originating cell type. ${ }^{11}$ Release of EVs allows cells to influence (patho)physiological processes over distance in contrast to cell-cell contact.

EVs transfer proteins, mRNA, miRNA and bioactive lipids from one cell to another cell 
by either fusion or internalisation with target cells. ${ }^{13}$ For example, monocyte-derived EVs are internalised by endothelial cells and activate the nuclear factor- $\mathrm{kB}$ $(\mathrm{NF \kappa B})$ pathway and expression of adhesion molecules on these endothelial cells, amplifying inflammation. ${ }^{14}$ EVs are procoagulant, as they carry phosphatidylserine on their membrane, which facilitates the assembly of components of the clotting cascade. ${ }^{15}$ In addition, EVs also carry the procoagulant protein tissue factor, which is primary cellular activator of the clotting cascade. ${ }^{16}$ It has been demonstrated that atherosclerotic plaques had 200-fold higher levels of EVs in comparison with plasma of the same study participants, ${ }^{17}$ suggesting an active role of EVs in atherothrombotic disease rather than a trigger of disease onset.

Virtually every cell is capable of producing EVs, including brain cells such as neurones and astrocytes. ${ }^{18}$ Little is known about the role EVs play in the development of brain atrophy or small vessel disease. However, microparticles, a subclass of EVs, have been shown to influence arterial stiffness ${ }^{19}$ which is associated with cerebral small vessel disease. ${ }^{20-22}$ Alternatively, plateletderived microparticles have been suggested to play a role in the formation of cerebral microthrombi, ${ }^{23}$ a known initiator of brain atrophy and subsequent cognitive decline. Exosomes, another subclass of EVs, have been shown to pass the blood-brain barrier (BBB) ${ }^{24} 25$ In a murine model, a specific gene knockdown in cerebro was achieved through the actions of peripherally infused modified exosomes containing specific RNA. ${ }^{24}$

We hypothesised that EV protein levels of cystatin C, serpin G1, serpin F2 and CD14 in peripherally circulating plasma EVs, which have been related to the occurrence of vascular disease previously, also are associated with the presence or increase of brain atrophy or with small vessel disease. Therefore, we investigated the relationship between levels of these four EV proteins extracted from plasma, brain parenchymal fraction (BPF) and WMLs in a cohort of patients with clinically manifest vascular disease.

\section{METHODS}

\section{SMART-MR study}

The study population consisted of patients participating in the Second Manifestations of ARTerial disease-MR (SMART-MR) study, a prospective cohort study aimed at investigating brain changes on MRI in 1309 patients with clinically manifest vascular disease. Details of the design and participants have been described elsewhere. ${ }^{126}$ In brief, between May 2001 and December 2005, all patients newly referred to the University Medical Center Utrecht, The Netherlands with manifest coronary artery disease (CAD), cerebrovascular disease (CVD), peripheral arterial disease (PAD) or an abdominal aortic aneurysm (AAA), and without MR contraindications, were invited to participate. CVD was defined as a recent diagnosis of ischaemic stroke, transient ischaemic attack or amaurosis fugax. CAD was defined as a recent diagnosis of angina pectoris, myocardial infarction or coronary revascularisation (coronary artery bypass graft or coronary angioplasty). PAD consisted of those with a clinical diagnosis of Fontaine stage 2, 3 or 4. AAA was defined as an AAA of $\geq 3.0 \mathrm{~cm}$ or recent aneurysm surgery.

Excluded were patients with a terminal disease, active malignancy, those not independent in daily activities and those referred back to the referring specialist immediately after one visit. After inclusion, the patients underwent a standardised vascular screening including assessment of vascular risk factors and non-invasive measurement of subclinical atherosclerosis in addition to MRI of the brain. Risk factors, medical history and functioning were assessed with questionnaires that the patients completed prior to their visit. Of the original 1309 patients comprising this cohort, 1232 successfully underwent MRI measurement. For 994 of these patients, material for EV protein level measurement could be retrieved and had at least one EV protein level measurement. Between January 2006 and May 2009, all the participants still alive $(n=1238)$ were invited for follow-up measurements, including a second MRI of the brain. For 534 patients, data on follow-up MRI as well as baseline EV protein levels were available; and written informed consent was obtained from all the participants.

\section{MRI protocol}

MR investigations were performed on a $1.5 \mathrm{~T}$ whole-body system (Gyroscan ACS-NT, Philips Medical Systems, Best, The Netherlands). The protocol consisted of a transversal T1-weighted gradient-echo sequence (repetition time (TR) / echo time (TE): 235/2 ms; flip angle, $80^{\circ}$ ), a transversal T2-weighted turbo spin-echo sequence (TR/TE: 2200/11 and 2200/100 ms; turbo factor 12), a transversal T2-weighted fluid attenuating inverse recovery (FLAIR) sequence (TR/TE/inversion time (TI): 6000/100/ $2000 \mathrm{~ms}$ ) and a transversal inversion recovery (IR) sequence (TR/TE/TI: 2900/22/410 ms) (field of view $\mathrm{mm}$; matrix size; slice thickness, $4 \mathrm{~mm}$; no gap; 38 slices).

\section{Brain segmentation}

The T1-weighted gradient echo, IR sequence and FLAIR sequence were used for brain segmentation with the probabilistic segmentation technique that has been described elsewhere. ${ }^{27} 28$ This segmentation programme distinguishes cortical grey matter, normal appearing white matter, sulcal and ventricular cerebrospinal fluid (CSF) and lesions. The results of the segmentation analysis were visually checked for the presence of infarctions and adapted if necessary to make a distinction between WMLs and infarction volumes. Total brain volume was calculated by summing the volumes of grey and normal appearing white matter and, if present, the volumes of WML and infarcts. All volumes cranial to the foramen magnum were included. As a result, the total brain volume includes both hemispheres, brainstem and cerebellum. Total intracranial volume (ICV) was calculated 
by summing the total brain volume and the volumes of the sulcal and ventricular CSF.

\section{White matter lesions}

Periventricular WMLs were defined as WML adjacent to or within $1 \mathrm{~cm}$ of the lateral ventricles. Deep WMLs were defined as lesions located in deep white matter tracts or without adjoined periventricular lesions. If white matter hyperintensities on T2-weighted images were also hypointense on T1-weighted and FLAIR images, they were considered infarcts and therefore distinguished from WML.

\section{Brain parameters}

Two brain parameters were used for analyses: WML, which was the sum of periventricular and deep WML in millilitres, expressed as percentage of ICV and BPF, which was determined by calculating the total brain volume in millilitres as percentage of ICV. By including the percentages of ICV instead of crude brain parameters, correction for differences in head size was applied.

\section{Extracellular vesicle measurements}

The complete measurement methods are described elsewhere. ${ }^{7}$ EVs were isolated using ExoQuick (SBI) according to the manufacturer's protocol. Briefly, $150 \mu \mathrm{L}$ EDTA plasma was centrifuged for $15 \mathrm{~min}$ at $3000 \mathrm{~g}$. The supernatant was filtered over a $0.45 \mu \mathrm{m}$ Spin-X filter (Corning), which was flushed with preheated phosphate buffered saline $\left(37^{\circ} \mathrm{C}\right)$ and $38 \mu \mathrm{L}$ ExoQuick solution was added to the filtrate. After vortexing, the sample was stored overnight at $4^{\circ} \mathrm{C}$. The following day, the sample was centrifuged at $1500 \mathrm{~g}$ for $30 \mathrm{~min}$ at room temperature. After removing the supernatant, the pellet was lysed in $100 \mu \mathrm{L}$ Roche Complete Lysis-M with protease inhibitors (EDTA free). Subsequently, the sample was filtered over a $0.22 \mu \mathrm{m}$ Spin-X filter (Corning) and protein level was determined using a Pierce BCA Protein Assay Kit (Pierce Biotechnology, Rockford, USA) before storing the sample at $-80^{\circ} \mathrm{C}$. After thawing, the lysed sample was diluted $20 \times$ with Roche complete lysis-M buffer. Of this diluted sample, $50 \mu \mathrm{L}$ was analysed in a multiplex immunoassay on levels of cystatin C, serpin G1, serpin F2 and CD14, using a Bio-Rad Bioplex 200 system as described elsewhere. ${ }^{29}$ Capture antibody, biotinylated detection antibody and antigen of all four proteins were purchased from research and development systems.

\section{Data analyses}

Central estimators and their variance measures were calculated for baseline characteristics. Multivariable linear regression was performed to assess the cross-sectional relationship between $\mathrm{EV}$ protein level in $\mathrm{pg} / \mathrm{mL}$ and WML in per cent or BPF in per cent. The fully adjusted model included age, gender, systolic blood pressure, smoking and type 2 diabetes, as these covariates are considered to be confounding factors in the suggested relationship between $\mathrm{EV}$ protein levels and measured structural brain changes.

To fulfil linear regression assumptions, WML volumes were naturally log-transformed as they showed skewed distributions. In order to directly compare the strengths of associations, linear regressions were performed per $\mathrm{SD}$ increase in $\mathrm{EV}$ protein level. Second, we assessed the prospective relationship between baseline EV protein levels and progression in brain parameters on MRI. This was carried out by relating baseline $\mathrm{EV}$ protein levels to follow-up WML or BPF. Besides adjustment for age, gender, systolic blood pressure, smoking and type 2 diabetes, these analyses were additionally adjusted for baseline WML or BPF and follow-up time. The results are expressed as linear regression coefficients and $95 \%$ CIs.

\section{RESULTS}

\section{Baseline characteristics}

The patient's characteristics are displayed in table 1 . Seventy-nine per cent of the initial patients were men and the mean age was $59 \pm 10$ years. The majority of the patients had a (recent) medical history of CAD (58\%), followed by CVD (26\%), PAD (24\%) and AAA (10\%). After a mean interval time of $3.9 \pm 0.4$ years, 534 patients underwent a second MRI of the brain. This follow-up cohort comprised $80 \%$ men and a mean baseline age of $58 \pm 9$ years, which corresponded with a mean follow-up age of $62 \pm 9$ years. For the baseline comparisons of the two groups, refer to online supplemental table S1.

\section{Cross-sectional association between EV protein levels and WML or BPF}

In the fully adjusted model, higher EV-cystatin $\mathrm{C}$ and EV-CD14 were associated with more volume of WML. Regression coefficients per SD EV-protein were 0.10 (95\% CI 0.04 to 0.17 ) for EV-cystatin C and 0.14 (95\% CI 0.07 to 0.20 ) for EV-CD14 (table 2). Also, higher EV-CD14 was associated with a statistically significantly lower BPF (regression coefficient per SD EV-CD14 -0.14 $(95 \%$ CI -0.27 to -0.01$)$; table 3$)$. SD increases of EV-serpin G1 and EV-serpin F2 were not related with WML or BPF at baseline.

In general, adjustment for age and gender in model 2 altered the effect estimates substantially, whereas the impact that systolic blood pressure, smoking and type 2 diabetes had on the occurrence relation was relatively small. Tests for interaction by age and gender yielded non-significant results (data not shown).

\section{Prospective associations between EV protein levels and of WIML or BPF}

In the fully adjusted model, higher EV-CD14 was associated with increase of WML volume (regression coefficient $=0.11(95 \%$ CI 0.04 to 0.18$))$ as is displayed in table 2. EV-cystatin C, EV-serpin G1 and EV-serpin F2 were not related with increase of WML or BPF. 
Table 1 Baseline patient characteristics

\begin{tabular}{|c|c|c|c|}
\hline & Baseline cohort $\mathrm{N}=994$ & Follow-up patients $\mathrm{N}=534$ & Non-FU patients $\mathrm{N}=460$ \\
\hline Age (years) ${ }^{\star}$ & $59 \pm 10$ & $58 \pm 9$ & $60 \pm 11$ \\
\hline Male gender, $\mathrm{n}(\%)$ & $784(79)$ & $426(80)$ & $358(78)$ \\
\hline Body mass index $\left(\mathrm{kg} / \mathrm{m}^{2}\right)^{*}$ & $26.9 \pm 3.8$ & $26.9 \pm 3.6$ & $26.8 \pm 4.1$ \\
\hline Waist circumference $(\mathrm{cm})^{*}$ & $95 \pm 11$ & $95 \pm 11$ & $96 \pm 12$ \\
\hline \multicolumn{4}{|l|}{ Blood pressure $(\mathrm{mm} \mathrm{Hg})^{*}$} \\
\hline Systolic & $144 \pm 22$ & $142 \pm 20$ & $145 \pm 23$ \\
\hline Diastolic & $83 \pm 12$ & $82 \pm 11$ & $83 \pm 12$ \\
\hline LDL cholesterol (mmol/L)* & $2.8 \pm 0.93$ & $2.8 \pm 0.90$ & $2.9 \pm 0.97$ \\
\hline HDL cholesterol $(\mathrm{mmol} / \mathrm{L})^{*}$ & $1.30 \pm 0.38$ & $1.31 \pm 0.38$ & $1.28 \pm 0.37$ \\
\hline Triglycerides (mmol/L)† & $1.47(1.09-2.07)$ & $1.41(1.05-2.07)$ & 1.47 (1.09-2.07) \\
\hline Glucose $(\mathrm{mmol} / \mathrm{L})^{*}$ & $6.3 \pm 1.9$ & $6.2 \pm 1.8$ & $6.4 \pm 1.9$ \\
\hline $\mathrm{HsCRP}(\mathrm{mmol} / \mathrm{L}) \dagger$ & $1.8(0.9-3.8)$ & $1.6(0.8-3.5)$ & $1.8(0.9-3.8)$ \\
\hline eGFR $\left(\mathrm{mL} / \mathrm{min} / 1.73 \mathrm{~m}^{2}\right)^{*}$ & $77.7 \pm 17.9$ & $79.7 \pm 17.1$ & $75.4 \pm 18.6$ \\
\hline Homocysteine $(\mu \mathrm{mol} / \mathrm{L})^{\star}$ & $14.0 \pm 6.0$ & $13.5 \pm 4.9$ & $14.6 \pm 7.0$ \\
\hline Prevalent type 2 diabetes, n (\%) & $156(16)$ & $71(13)$ & $85(19)$ \\
\hline Metabolic syndrome, n (\%)‡ & 369 (37) & $184(35)$ & $185(40)$ \\
\hline \multicolumn{4}{|l|}{ Smoking, $\mathrm{n}(\%)$} \\
\hline Never & $170(17)$ & $100(18)$ & $70(15)$ \\
\hline Ever & $454(46)$ & $257(48)$ & $197(43)$ \\
\hline Current & $370(37)$ & $177(33)$ & $193(42)$ \\
\hline Pack years smoking ${ }^{\star}$ & $23.0 \pm 20.5$ & $23.0 \pm 20.1$ & $23.1 \pm 21.0$ \\
\hline \multicolumn{4}{|l|}{ History of vascular disease, $\mathrm{n}(\%)$} \\
\hline Cerebrovascular disease & $261(26)$ & $144(27)$ & $117(25)$ \\
\hline Coronary artery disease & $580(58)$ & $325(61)$ & $255(55)$ \\
\hline Peripheral artery disease & $241(24)$ & $108(20)$ & $133(29)$ \\
\hline Aneurysm of the abdominal aorta & $99(10)$ & $37(7)$ & $62(14)$ \\
\hline \multicolumn{4}{|l|}{ Medication, n (\%) } \\
\hline Platelet-aggregation inhibitors & $740(74)$ & $407(76)$ & $333(72)$ \\
\hline Blood pressure-lowering agents & $702(71)$ & $382(72)$ & $320(70)$ \\
\hline Lipid-lowering agents & $682(69)$ & $388(73)$ & $294(64)$ \\
\hline Oral anticoagulants & $80(8)$ & $37(7)$ & $43(9)$ \\
\hline White matter lesions $(\log \%)^{\star}$ & $-2.1(1.1)$ & $-2.3(1.1)$ & $-1.9(1.1)$ \\
\hline Brain parenchymal fraction $(\%)^{*}$ & $79(3)$ & $79(3)$ & $79(3)$ \\
\hline \multicolumn{4}{|c|}{$\begin{array}{l}\text { `Mean } \pm \text { SD. } \\
\text { †Median (IQR). } \\
\text { †Defined according to the National Cholesterol Education Programme ATPIII-revised guidelines. } \\
\text { eGFR, epidermal growth factor receptor; HDL, high-density lipoprotein; HsCRP, high-sensitivity C reactive protein; LDL, low-density } \\
\text { lipoprotein. }\end{array}$} \\
\hline
\end{tabular}

\section{DISCUSSION}

In patients with various clinical manifestations of vascular disease, EV protein levels of cystatin C and CD14 in plasma are associated with larger WML and more brain atrophy. Furthermore, higher EV-CD14 levels are associated with an increase in WML during 4 years of follow-up. This relation is independent of age, gender, systolic blood pressure, smoking and type 2 diabetes.

The role of cystatin $\mathrm{C}$, a cysteine protease inhibitor, in the process of degenerative disorders in the brain is unclear. In vitro and murine studies have shown that cystatin $\mathrm{C}$ binds to amyloid- $\beta$ (a $\beta)$, resulting in the inhibition of a $\beta$ deposition, ${ }^{30-32}$ the characteristic component of the neuritic plaques that identify patients with Alzheimer's disease. This protective role of cystatin C was supported in a cohort study ${ }^{33}$ where lower levels of serum cystatin $\mathrm{C}$ were associated with higher risk for future Alzheimer's disease in men. However, higher levels of serum cystatin $\mathrm{C}$ have also been associated with cognitive decline ${ }^{34}$ and with $\mathrm{WML}^{36}$ in large population-based cohort studies. In WML, the cystatin $\mathrm{C}$ expression is upregulated in astrocytes, presumably due to a self-defence response in the process of white matter degeneration $^{37}$ Our results, based on EV-cystatin C, show similar results as increasing $\mathrm{EV}$-cystatin $\mathrm{C}$ is related to increased volume of WML. Cystatin $\mathrm{C}$ is secreted by all human tissues ${ }^{38}$ which presumably concomitantly shed cystatin $\mathrm{C}^{+}$EVs in order to directly influence more distant processes.

CD14 is a cofactor for Toll-like receptor 4, which regulates $\mathrm{NF \kappa B}$ expression, indicating a role for CD14 in inflammation. ${ }^{39}$ CD14 is expressed on monocytes ${ }^{40}$ and it is therefore assumable that $\mathrm{CD} 14^{+} \mathrm{EVs}$ originate from these monocytes. In our study, EV-CD14 levels were related to the volume and increase of WML. This indicates an EV-initiated inflammatory response in dealing 
Table 2 EV protein levels and WMLs

\begin{tabular}{|c|c|c|c|}
\hline & \multirow[b]{2}{*}{ Model } & \multicolumn{2}{|l|}{ WML } \\
\hline & & WML at baseline $n=994$ & WML at follow-up* $n=534$ \\
\hline EV-cystatin C (pg/ug) & I & $0.27(0.20-0.34)$ & $0.06(-0.02-0.13)$ \\
\hline Mean 10.6 & II & $0.10(0.04-0.17)$ & $0.01(-0.06-0.08)$ \\
\hline SD 5.3 & III & $0.10(0.04-0.17)$ & $0.01(-0.06-0.08)$ \\
\hline EV-serpin G1 (pg/ug) & 1 & $-0.03(-0.10-0.05)$ & $0.02(-0.05-0.08)$ \\
\hline Mean 142.2 & II & $-0.02(-0.08-0.04)$ & $0.02(-0.04-0.08)$ \\
\hline SD 85.6 & III & $-0.03(-0.08-0.05)$ & $0.03(-0.03-0.09)$ \\
\hline EV-serpin F2 (pg/ug) & 1 & $0.01(-0.066-0.08)$ & $-0.01(-0.08-0.05)$ \\
\hline Mean 43.3 & II & $0.03(-0.034-0.09)$ & $0.01(-0.06-0.07)$ \\
\hline SD 30.4 & III & $0.03(-0.035-0.09)$ & $0.01(-0.05-0.07)$ \\
\hline EV-CD 14 (pg/pg) & I & $0.23(0.16-0.30)$ & $0.12(0.04-0.18)$ \\
\hline Mean 12.2 & II & $0.14(0.08-0.20)$ & $0.10(0.03-0.17)$ \\
\hline SD 3.9 & III & $0.14(0.07-0.20)$ & $0.11(0.04-0.18)$ \\
\hline
\end{tabular}

Bold typeface indicates statistically significant results.

Regression coefficients: increase in WML (log\%) per 1SD increase in EV protein level ( $\mathrm{pg} / \mathrm{mL})$.

Model I: univariable model.

Model II: adjustment for age and gender.

Model III: Model II with additional adjustment for systolic blood pressure, pack years smoking and prevalent type 2 diabetes mellitus.

${ }^{*}$ Models include additional adjustment for baseline WML and follow-up time.

EV, extracellular vesicle; WMLs, white matter lesions

with WML. These findings do not stand alone as several inflammatory biomarkers such as lipoprotein-associated phospholipase A2 and myeloperoxidase (MPO) have been associated with WML. ${ }^{41}$ Although the effects of EV-CD14 on WML and BPF have not been assessed previously, soluble CD14 has been associated with cognitive impairment and brain atrophy in patients with HIV. ${ }^{42}$ Likewise, higher plasma levels of EV-CD14 were inversely related to BPF at baseline in our study.

EV-Serpin G1 (C1-inhibitor) and EV-Serpin F2 $(\alpha 2$-antiplasmin) were not associated with WML or BPF in our study, suggesting no substantial role of (inhibited) fibrinolysis in the pathophysiology surrounding WML or brain atrophy. To our understanding, this is the first report on these serpins and their potential role in the aetiology of WML and brain atrophy.

Whether and how EVs or EV protein levels might directly influence ischaemic WMLs or brain volume is not known. Several mechanisms are proposed. We assume that EVs have BBB penetrating properties, based on recent data regarding exosomes. ${ }^{24}{ }^{25}$ It could also be that EVs interact with endothelial cells through receptormediated endocytosis. Once fused with these endothelial cells, EV protein levels might activate inflammation

Table 3 Extracellular vesicle protein levels and BPF

\begin{tabular}{|c|c|c|c|}
\hline & \multirow[b]{2}{*}{ Model } & \multicolumn{2}{|l|}{ BPF } \\
\hline & & BPF at baseline $n=994$ & BPF at follow-up ${ }^{*} n=534$ \\
\hline EV-cystatin C (pg/ug) & I & $-0.69(-0.86--0.51)$ & $-0.15(-0.26--0.04)$ \\
\hline Mean 10.6 & II & $-0.12(-0.26-0.02)$ & $-0.06(-0.16-0.04)$ \\
\hline SD 5.3 & III & $-0.11(-0.24-0.03)$ & $-0.05(-0.16-0.05)$ \\
\hline EV-serpin G1 (pg/ug) & 1 & $-0.00(-0.18-0.17)$ & $0.04(-0.05-0.14)$ \\
\hline Mean 142.2 & II & $0.01(-0.12-0.14)$ & $0.02(-0.06-0.11)$ \\
\hline SD 85.6 & III & $0.10(-0.12-0.14)$ & $0.03(-0.06-0.11)$ \\
\hline 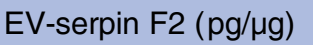 & 1 & $0.05(-0.12-0.23)$ & $0.06(-0.04-0.16)$ \\
\hline Mean 43.3 & II & $-0.10(-0.23-0.03)$ & $-0.01(-0.10-0.08)$ \\
\hline SD 30.4 & III & $-0.06(-0.19-0.07)$ & $0.01(-0.09-0.10)$ \\
\hline EV-CD $14(\mathrm{pg} / \mu \mathrm{g})$ & 1 & $-0.45(-0.62--0.28)$ & $-0.06(-0.17-0.05)$ \\
\hline Mean 12.2 & II & $-0.19(-0.32--0.06)$ & $-0.05(-0.15-0.05)$ \\
\hline SD 3.9 & III & $-0.14(-0.27--0.01)$ & $-0.03(-0.13-0.07)$ \\
\hline
\end{tabular}

Bold typeface indicates statistically significant results.

Regression coefficients: increase in BPF (\%) per 1SD increase in EV protein level (pg/mL).

Model I: univariable model.

Model II: adjustment for age and gender.

Model III: model II with additional adjustment for systolic blood pressure, pack years smoking and prevalent type 2 diabetes mellitus.

*Models include additional adjustment for baseline WML and follow-up time.

BPF, brain parenchymal fraction; EV, extracellular vesicle; WML, white matter lesion. 
cascade signalling, leading to vascular damage and subsequent arterial stiffness. It might also activate haemostasis cascade signalling leading to the formation of (micro) thrombi. Alternatively, through endocytosis by endothelial cells, EV protein levels might influence the structural integrity of the endothelial layer, resulting in a greater BBB permeability. Neurodegenerative disorders such as Alzheimer's disease ${ }^{43}$ and multiple sclerosis ${ }^{44}$ have been associated with BBB integrity loss. The mechanism behind this loss is unclear and perhaps $\mathrm{EV}$ vesicles play a role within this process. Future work will have to test these hypotheses. If true causation between $\mathrm{EV}$ protein levels and brain changes would be the case, strategies on influencing EV protein levels should be developed.

The strengths of the present prospective cohort study include the relatively large sample size with various EV protein measurements and MRIs of the brain at baseline and 3.9 years follow-up, which makes reversed causality less likely. Another strength of the study is the use of automated segmentation techniques to obtain brain parameters, which provides more precise and objective estimates than visual rating scales ${ }^{45}$ and enables accurate measurement of small volume changes over time. ${ }^{46}$

Potential study limitations should also be considered. First, data of only $54 \%$ of the surviving cohort was used to measure change in WML or BPF. The patients who were physically able to undergo the follow-up MRI were most likely healthier than those who did not participate, which might have led to the dilution of associations. Second, only four of the numerous proteins on the surface or within EVs were measured. It could be that besides these vascular risk markers, various other EV proteins have their aetiology in the structural brain changes. Third, we assume that plasma EVs which hold the proteins measured in the present study have the ability to cross the BBB in order to have their effects on the brain, influencing WML and BPF. Unfortunately, no data are available whether these EVs are indeed present within the brain, and it would be interesting to know whether these EV proteins are present in CSF and have a non-cerebral origin. If these EVs can truly pass the BBB and influence the pathophysiological processes in the brain, it automatically gives rise to potential therapeutical purposes analogous to exosomes, as these vesicles can deliver complex drugs directly into the brain, a key step in the treatment of brain diseases or brain changes. ${ }^{47}$

In conclusion, EV-cystatin $\mathrm{C}$ and EV-CD14 levels are related with the volume of WML and with BPF on the brain MRI. EV-CD14 levels are related with an increase in the total volume of WML during follow-up. EV proteins levels may be causally related to brain changes in patients with clinically manifest vascular disease.

\footnotetext{
Author affiliations

${ }^{1}$ Department of Vascular Medicine, University Medical Center Utrecht (UMC Utrecht), Utrecht, The Netherlands

${ }^{2}$ Experimental Cardiology Laboratory, UMC Utrecht, Utrecht, The Netherlands ${ }^{3}$ Interuniversity Cardiology Institute of the Netherlands (ICIN) Utrecht, Utrecht, The Netherlands
}

${ }^{4}$ Surgery (NUS) and Cardiovascular Research Institute (NUH) Singapore, Singapore, Singapore

${ }^{5}$ Department of Neurology, Utrecht Stroke Centre, Rudolf Magnus Institute of Neuroscience, UMC Utrecht, Utrecht, The Netherlands

${ }^{6}$ Julius Center for Health Sciences and Primary Care, UMC Utrecht, Utrecht, The Netherlands

Acknowledgements The authors gratefully acknowledge the members of the Second Manifestations of ARTerial disease (SMART) study group of UMC Utrecht: PA Doevendans, MD, PhD, Department of Cardiology; A Algra, MD, PhD; YvdG; DE Grobbee, MD, PhD, GEHM Rutten, MD, PhD, Julius Center for Health Sciences and Primary Care; LJK; WPTM Mali, MD, PhD, Department of Radiology; FL Moll, MD, PhD, Department of Vascular Surgery; FLJV. The authors also thank AH Schoneveld, L Collee and S van der Weg for the measurement of the plasma extracellular vesicle proteins.

Contributors DAK, LJK, CSPMU and FLJV participated in conception and design, or analysis and interpretation of the data. DAK, DPVdK, LJK, CSPMU, YvdG, GP, MIG and FLJV participated in drafting the article or revising it critically for important intellectual content and final approval of the version to be published.

Funding This work was financially supported by the UMC Utrecht Vascular Prevention Project.

\section{Competing interests None.}

Patient consent Obtained.

Ethics approval The Second Manifestations of ARTerial disease-MR (SMART-MR) study was approved by the ethics committee of the University Medical Center Utrecht-Medical Ethics Committee.

Provenance and peer review Not commissioned; externally peer reviewed.

Data sharing statement Additional unpublished data from the Second Manifestations of ARTerial disease (SMART) study in general are available to all members of the SMART study group.

Open Access This is an Open Access article distributed in accordance with the Creative Commons Attribution Non Commercial (CC BY-NC 3.0) license, which permits others to distribute, remix, adapt, build upon this work noncommercially, and license their derivative works on different terms, provided the original work is properly cited and the use is non-commercial. See: http:// creativecommons.org/licenses/by-nc/3.0/

\section{REFERENCES}

1. Geerlings $\mathrm{MI}$, Appelman $\mathrm{AP}$, Vincken $\mathrm{KL}$, et al. Brain volumes and cerebrovascular lesions on MRI in patients with atherosclerotic disease. The SMART-MR study. Atherosclerosis 2010;210:130-6.

2. Breteler MM, van Swieten JC, Bots ML, et al. Cerebral white matter lesions, vascular risk factors, and cognitive function in a population-based study: the Rotterdam Study. Neurology 1994;44:1246-52.

3. Vinkers DJ, Stek ML, van der Mast RC, et al. Generalized atherosclerosis, cognitive decline, and depressive symptoms in old age. Neurology 2005;65:107-12.

4. Breteler MM, Claus JJ, Grobbee DE, et al. Cardiovascular disease and distribution of cognitive function in elderly people: the Rotterdam Study. BMJ 1994;308:1604-8.

5. Nash DT, Fillit H. Cardiovascular disease risk factors and cognitive impairment. Am J Cardiol 2006;97:1262-5.

6. Viswanathan A, Rocca WA, Tzourio C. Vascular risk factors and dementia: how to move forward? Neurology 2009;72:368-74.

7. Kanhai DA, Visseren FL, van der Graaf $Y$, et al. Microvesicle protein levels are associated with increased risk for future vascular events and mortality in patients with clinically manifest vascular disease. Int J Cardiol 2013;168:2358-63.

8. Sinning JM, Losch J, Walenta K, et al. Circulating CD31+/Annexin V + microparticles correlate with cardiovascular outcomes. Eur Heart $J$ 2011;32:2034-41.

9. Cocucci E, Racchetti G, Meldolesi J. Shedding microvesicles: artefacts no more. Trends Cell Biol 2009;19:43-51.

10. van der Vlist EJ, Nolte-'t Hoen EN, Stoorvogel W, et al. Fluorescent labeling of nano-sized vesicles released by cells and subsequent 
quantitative and qualitative analysis by high-resolution flow cytometry. Nat Protoc 2012;7:1311-26.

11. Jy W, Horstman LL, Jimenez JJ, et al. Measuring circulating cell-derived microparticles. J Thromb Haemost 2004;2:1842-51.

12. Morel $\mathrm{O}$, Morel $\mathrm{N}$, Hugel $\mathrm{B}$, et al. The significance of circulating microparticles in physiology, inflammatory and thrombotic diseases. Rev Med Interne 2005;26:791-801.

13. Martinez MC, Tual-Chalot S, Leonetti D, et al. Microparticles: targets and tools in cardiovascular disease. Trends Pharmacol Sci 2011;32:659-65.

14. Wang JG, Williams JC, Davis BK, et al. Monocytic microparticles activate endothelial cells in an IL-1 $\beta$-dependent manner. Blood 2011;118:2366-74.

15. Owens AP III, Mackman N. Microparticles in hemostasis and thrombosis. Circ Res 2011;108:1284-97.

16. Mackman N, Tilley RE, Key NS. Role of the extrinsic pathway of blood coagulation in hemostasis and thrombosis. Arterioscler Thromb Vasc Biol 2007;27:1687-93.

17. Leroyer AS, Isobe $\mathrm{H}$, Lesèche $\mathrm{G}$, et al. Cellular origins and thrombogenic activity of microparticles isolated from human atherosclerotic plaques. J Am Coll Cardiol 2007;49:772-7.

18. Fauré J, Lachenal $\mathrm{G}$, Court $\mathrm{M}$, et al. Exosomes are released by cultured cortical neurones. Mol Cell Neurosci 2006;31:642-8.

19. Amabile N, Guérin AP, Leroyer A, et al. Circulating endothelial microparticles are associated with vascular dysfunction in patients with end-stage renal failure. J Am Soc Nephrol 2005;16:3381-8.

20. O'Rourke MF, Safar ME. Relationship between aortic stiffening and microvascular disease in brain and kidney: cause and logic of therapy. Hypertension 2005;46:200-4.

21. Ohmine $\mathrm{T}$, Miwa $\mathrm{Y}, \mathrm{Yao} \mathrm{H}$, et al. Association between arteria stiffness and cerebral white matter lesions in community-dwelling elderly subjects. Hypertens Res 2008;31:75-81.

22. Kuo HK, Chen CY, Liu HM, et al. Metabolic risks, white matter hyperintensities, and arterial stiffness in high-functioning healthy adults. Int J Cardiol 2010;143:184-91.

23. Jimenez JJ, Jy W, Mauro LM, et al. Elevated endothelial microparticles in thrombotic thrombocytopenic purpura: findings from brain and renal microvascular cell culture and patients with active disease. Br J Haematol 2001;112:81-90.

24. Alvarez-Erviti L, Seow $\mathrm{Y}$, Yin $\mathrm{H}$, et al. Delivery of siRNA to the mouse brain by systemic injection of targeted exosomes. $\mathrm{Nat}$ Biotechnol 2011;29:341-5.

25. Graner MW, Alzate O, Dechkovskaia AM, et al. Proteomic and immunologic analyses of brain tumor exosomes. FASEB $J$ 2009;23:1541-57.

26. Simons PC, Algra A, van de Laak MF, et al. Second manifestations of ARTerial disease (SMART) study: rationale and design. Eur $J$ Epidemiol 1999;15:773-81.

27. Anbeek $\mathrm{P}$, Vincken $\mathrm{KL}$, van Osch $\mathrm{MJ}$, et al. Probabilistic segmentation of white matter lesions in MR imaging. Neuroimage 2004;21:1037-44

28. Anbeek P, Vincken KL, van Bochove GS, et al. Probabilistic segmentation of brain tissue in MR imaging. Neuroimage 2005;27:795-804.
29. Schipper HS, de Jager W, van Dijk ME, et al. A multiplex immunoassay for human adipokine profiling. Clin Chem 2010;56:1320-8.

30. Sastre M, Calero M, Pawlik M, et al. Binding of cystatin C to Alzheimer's amyloid beta inhibits in vitro amyloid fibril formation. Neurobiol Aging 2004;25:1033-43.

31. Kaeser SA, Herzig MC, Coomaraswamy J, et al. Cystatin C modulates cerebral beta-amyloidosis. Nat Genet 2007;39:1437-9.

32. Mi W, Pawlik M, Sastre M, et al. Cystatin C inhibits amyloid-beta deposition in Alzheimer's disease mouse models. Nat Genet 2007;39:1440-2.

33. Sundelöf J, Arnlöv J, Ingelsson E, et al. Serum cystatin C and the risk of Alzheimer disease in elderly men. Neurology 2008;71:1072-9.

34. Yaffe K, Lindquist K, Shlipak MG, et al. Cystatin C as a marker of cognitive function in elders: findings from the health $A B C$ study. Ann Neurol 2008;63:798-802.

35. Rajagopalan $\mathrm{P}$, Refsum H, Hua X, et al. Alzheimer's disease neuroimaging initiative. Mapping creatinine- and cystatin C-related white matter brain deficits in the elderly. Neurobiol Aging 2013;34:1221-30.

36. Wada M, Nagasawa $\mathrm{H}$, Kawanami $\mathrm{T}$, et al. Cystatin $\mathrm{C}$ as an index of cerebral small vessel disease: results of a cross-sectional study in community-based Japanese elderly. Eur J Neurol 2010;17:383-90.

37. Umegae N, Nagai A, Terashima M, et al. Cystatin C expression in ischemic white matter lesions. Acta Neurol Scand 2008;118:60-7.

38. Mussap M, Plebani M. Biochemistry and clinical role of human cystatin C. Crit Rev Clin Lab Sci 2004;41:467-550.

39. Jiang Q, Akashi S, Miyake K, et al. Lipopolysaccharide induces physical proximity between CD14 and toll-like receptor 4 (TLR4) prior to nuclear translocation of NF-kappa B. J Immunol 2000;165:3541-4.

40. Ziegler-Heitbrock L, Ancuta P, Crowe S, et al. Nomenclature of monocytes and dendritic cells in blood. Blood 2010;116:e74-80.

41. Wright CB, Moon Y, Paik MC, et al. Inflammatory biomarkers of vascular risk as correlates of leukoariosis. Stroke 2009;40:3466-71.

42. Ryan LA, Zheng J, Brester M, et al. Plasma levels of soluble CD14 and tumor necrosis factor-alpha type II receptor correlate with cognitive dysfunction during human immunodeficiency virus type 1 infection. J Infect Dis 2001;184:699-706.

43. Zipser BD, Johanson CE, Gonzalez L, et al. Microvascular injury and blood-brain barrier leakage in Alzheimer's disease. Neurobiol Aging 2007;28:977-86.

44. Waubant E. Biomarkers indicative of blood-brain barrier disruption in multiple sclerosis. Dis Markers 2006;22:235-44.

45. Yoshita M, Fletcher E, DeCarli C. Current concepts of analysis of cerebral white matter hyperintensities on magnetic resonance imaging. Top Magn Reson Imaging 2005;16:399-407.

46. van den Heuvel DM, ten Dam VH, de Craen AJ, et al. PROSPER Study Group. Measuring longitudinal white matter changes: comparison of a visual rating scale with a volumetric measurement. Am J Neuroradiol 2006;27:875-8.

47. Wood MJ, O'Loughlin AJ, Samira L. Exosomes and the blood-brain barrier: implications for neurological diseases. Ther Deliv 2011;2:1095-9. 